\title{
Investigations on the microbial catabolism of the organic sulfur compounds TDP and DTDP in Ralstonia eutropha $\mathrm{H16}$ employing DNA microarrays
}

\author{
Katja Peplinski • Armin Ehrenreich • \\ Christina Döring • Mechthild Bömeke • \\ Alexander Steinbüchel
}

Received: 2 August 2010 /Revised: 5 September 2010 /Accepted: 8 September 2010 /Published online: 6 October 2010

(C) Springer-Verlag 2010

\begin{abstract}
In this study, we have investigated the transcriptome of Ralstonia eutropha H16 during cultivation with gluconate in presence of 3,3'-thiodipropionic acid (TDP) or 3,3'-dithiodipropionic acid (DTDP) during biosynthesis of poly(3-hydroxybutyrate-co-3-mercaptopropionate). Genome-wide transcriptome analyses revealed several genes which were upregulated during cultivation in presence of the above-mentioned compounds. Obtained data strongly suggest that two ABC-type transport system and three probable extracytoplasmic solute receptors mediate the uptake of TDP and DTDP, respectively. In addition, genes encoding the hydrolase $S$-adenosylhomocysteinase AhcY and the thioldisulfide interchange proteins DsbA, DsbD, and FrnE were upregulated during cultivation on DTDP and, in case of
\end{abstract}

Accession numbers Microarray data are available in the

ArrayExpress database (www.ebi.ac.uk/arrayexpress) under accession number E-MEXP-2744.

Electronic supplementary material The online version of this article (doi:10.1007/s00253-010-2915-6) contains supplementary material, which is available to authorized users.

K. Peplinski · A. Steinbüchel $(\square)$

Institut für Molekulare Mikrobiologie und Biotechnologie,

Westfälische Wilhelms-Universität Münster,

Corrensstrasse 3,

48149 Münster, Germany

e-mail: steinbu@uni-muenster.de

A. Ehrenreich

Institut für Mikrobiologie, Technische Universität München,

Am Hochanger 4,

85354 Freising, Germany

C. Döring $\cdot$ M. Bömeke

Institut für Mikrobiologie und Genetik,

Georg-August-Universität Göttingen,

37077 Göttingen, Germany
AhcY and FrnE, on TDP as well. It is assumed that the corresponding enzymes are involved in the cleavage of TDP and DTDP. Several genes of the fatty acid metabolism exhibited increased expression levels: genes encoding two acetyltransferases, a predicted acyltransferase, the acetoacetyl-CoA reductase phaB3, an enoyl-CoA hydratase as well as an acyl dehydratase, an acetyl-CoA synthetase, two acyl-CoA dehydrogenases, the methylmalonyl-CoA mutase encoded by $s b m 1$ and $s b m 2$ and phaY1 were detected. Furthermore, ORF H16_A0217 encoding a hypothetical protein and exhibiting $54 \%$ amino acids identical to an acyl-CoA thioesterase from Saccharomonospora viridis was found to be highly upregulated. As the 2-methylcitrate synthase PrpC exhibited a three- to fourfold increased activity in cells grown in presence of TDP or DTDP as compared to gluconate, metabolization of the cleavage products $3 \mathrm{MP}$ and 3-hydroxypropionate to propionyl-CoA is proposed.

Keywords 3,3'-dithiodipropionic acid · 2-methylcitric acid cycle $\cdot$ Poly(3-hydroxybutyrate) Polythioester $\cdot$ Ralstonia eutropha $\mathrm{H} 16 \cdot 3,3$ '-thiodipropionic acid

\section{Introduction}

Polyhydroxyalkanoates (PHAs) are linear polyesters which occur in many bacteria as storage compounds for carbon and energy. They are accumulated as water-insoluble inclusions in the cytoplasm in response to physiological stress such as oxygen or nitrogen deficiency and if a carbon source is present in excess at the same time. Poly(3hydroxybutyrate), poly(3HB), was the first identified PHA (Lemoigne 1926) and is the best-studied storage compound 
in prokaryotes. In addition to $3 \mathrm{HB}$, approximately 150 other hydroxyalkanoic acids have been identified as PHA constituents (Steinbüchel and Valentin 1995; Pötter and Steinbüchel 2005). Since 2001, polythioesters (PTEs) consisting of mercaptoalkanoic acids, are known as a new class of structurally related biopolymers with thioester instead of oxoester linkages in the backbone (Lütke-Eversloh et al. 2001a). The physical characteristics of PTEs such as thermal properties, solubility, and crystallinity deviate considerably from those of the corresponding oxoesters (Lütke-Eversloh et al. 2002; Kawada et al. 2003). One remarkable difference to PHAs is the non-biodegradability of PTE homopolymers. Whereas PHAs are degraded by many microorganisms by PHA depolymerases into simple organic compounds (Jendrossek and Handrick 2002), PTE homopolymers are persistent (Kim et al. 2005). Only investigations on the degradation of a copolymer of 3-hydroxybutyrate and 3-mercaptopropionate (3MP), poly(3HB-co-3MP), revealed new bacterial strains able to grow with this heteropolymer as sole carbon source by cleaving the oxoester bonds but not the thioester bonds (Elbanna et al. 2004).

The Gram-negative and facultative chemolithoautotrophic bacterium Ralstonia eutropha is probably the beststudied microorganism regarding PHA metabolism. Poly (3HB) biosynthesis is mediated by the PHA operon, comprising the genes for a $\beta$-ketothiolase ( $p h a A$ ), an acetoacetyl-CoA reductase (phaB) and the PHA synthase $(p h a C)$. The latter is the key enzyme of PHA biosynthesis and exhibits broad substrate specificity (Rehm 2003). Whereas $p h a C$ is essential for PHA biosynthesis, phaA and $p h a B$ can be replaced by isoenzymes (Slater et al. 1998; Lindenkamp et al. 2010). When cultivating cells of $R$. eutropha H16 under storage conditions with 3mercaptoalkanoic acids in addition to fructose or gluconate as carbon source, polyesters containing sulfur in the backbone of the polymer are synthesized. With 3MP as precursor substrate, the accumulation of copolymers consisting of 3-hydroxybutyrate and 3-mercaptopropionate, poly(3HBco-3MP), was shown, consisting of up to $40 \mathrm{~mol} \%$ of $3 \mathrm{MP}$ (Lütke-Eversloh et al. 2001a, b; Lütke-Eversloh and Steinbüchel 2003b). Variations of the copolymer composition could be obtained by supplying 3-mercaptobutyrate (3MB) or 3-mercaptovalerate (3MV) as precursor substrates. In addition to 3MP, R. eutropha H16 is also able to use 3,3'thiodipropionic acid (TDP) and 3,3'-dithiodipropionic acid (DTDP) as precursor substrates for biosynthesis of poly (3HB-co-3MP). Whereas 3MP was shown to inhibit growth of $R$. eutropha at a concentration of $0.1 \%(v / v)$ in the medium, TDP and DTDP exerted no inhibitory effects at concentrations of up to $1 \%(w / v)$ (Lütke-Eversloh and Steinbüchel 2003b).

Until now, relatively little is known about the metabolic pathway for degradation of the organic sulfur compounds mentioned above and biosynthesis of PTEs, respectively. Due to the incorporation of $3 \mathrm{MP}$ in the copolymer, cleavage of TDP into 3MP and 3HP by a yet unknown sulfide hydrolase is proposed, whereas DTDP is probably cleaved in two molecules 3MP by an unknown disulfide reductase (Fig. 1) (Lütke-Eversloh et al. 2001a; LütkeEversloh and Steinbüchel 2003a).

Very recently, the conversion of 3MP into 3-sulfinopropionate (3SP) was shown for the cysteine dioxygenase CdoA from $R$. eutropha H16 in recombinant Escherichia coli cells (Bruland et al. 2009). In addition to R. eutropha, the catabolism of TDP and DTDP was also intensely investigated in the recently described bacteria Variovorax paradoxus strain TBEA6 and Advenella mimigardefordensis strain DPN $7^{\mathrm{T}}$ (Bruland et al. 2009; Wübbeler et al. 2006, 2008). These studies led to a proposed degradation pathway from DTDP and TDP via 3MP, 3SP, and 3SP-CoA towards propionyl-CoA. The catabolism of propionyl-CoA via the 2-methylcitric acid cycle was strongly proposed for A. mimigardefordensis (Wübbeler et al. 2008).

Non-biodegradable, persistent polymers are valuable for certain applications such as permanent implants in medical applications or special technical applications in construction and automobiles (Steinbüchel 2005). For this reason, an indepth elucidation of PTE biosynthesis and of the catabolism of various organic sulfur compounds is required. To obtain more insights into the catabolism of the sulfur-containing precursor substrates and in the uptake of these compounds into the cells as well as in the enzymes involved in the biosynthesis of PTE homo- and copolymers, genome-wide transcriptome analyses were performed.

\section{Material and methods}

Bacterial strains and growth conditions

Cells of $R$. eutropha $\mathrm{H} 16$ were cultivated at $30^{\circ} \mathrm{C}$ in 21 Erlenmeyer flasks with baffles containing $400 \mathrm{ml}$ mineral salts medium (Schlegel et al. 1961), with $1 \%(w / v)$ sodium gluconate as sole carbon source. The ammonia concentration was $0.05 \%(w / v)$ to promote PHA accumulation. In addition, TDP or DTDP $(1 \% w / v)$ were used as second, sulfurcontaining carbon source for poly(3HB-co-3MP) biosynthesis. Growth of cells was measured in a Klett-Summerson photometer using filter no. $54(520-580 \mathrm{~nm})$. Cells were harvested in the stationary growth phase after $24,48,72$, and $96 \mathrm{~h}$ by centrifugation $\left(15 \mathrm{~min}, 4,000 \mathrm{rpm}, 4^{\circ} \mathrm{C}\right)$.

RNA isolation and cDNA synthesis

Harvested cells were washed in $0.9 \%(w / v)$ sodium chloride, directly shock-frozen in liquid nitrogen, and 
<smiles>[R]C(=O)C(=O)O</smiles>

Acetyl-CoA<smiles>CC(C)(C)c1ccccc1S(=O)(=O)O</smiles><smiles>CC(=O)CC(=O)C(=O)O</smiles>

Acetoacetyl-CoA

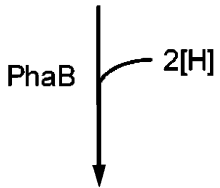<smiles>CC(O)CC(=O)C(=O)O</smiles>

3-Hydroxybutyryl-CoA

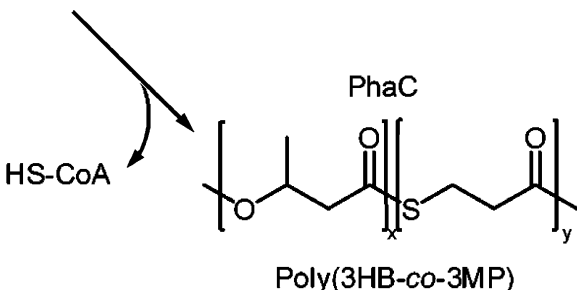<smiles>O=C([O-])CCSCCC(=O)[O-]</smiles>

3,3'-Thiodipropionate<smiles>CC(CO)(CO)CCCCOC(=O)CCO</smiles>

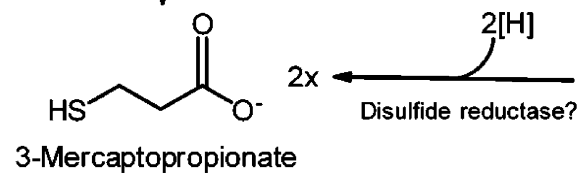<smiles>O=C(O)CCSSCCC(=O)O</smiles>

3,3'-Dithiodipropionate

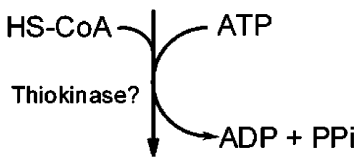<smiles>O=C(O)C(=O)CCS</smiles>

3-Mercaptopropionyl-CoA

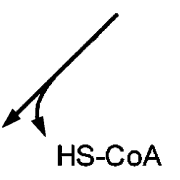

HS-CoA

Fig. 1 Overview of the biosynthesis pathways of heteropolythioester in R. eutropha H16 as proposed by Lütke-Eversloh and Steinbüchel (2004)

stored at $-70^{\circ} \mathrm{C}$. RNA was isolated by using the RNeasy mini kit (Qiagen, Hilden, Germany) and zirconia-silica beads (Roth, Karlsruhe, Germany) for mechanical disruption (Peplinski et al. 2010). Total RNA $(25 \mu \mathrm{g})$ were used for random hexamer-primed synthesis of fluorescencelabeled cDNA by reverse transcription using the CyScribe First-strand cDNA labeling kit and the fluorescent nucleotide analogous FluoroLink Cy3-dUTP and Cy5-dUTP (GE Healthcare).

\section{Microarray hybridization and scanning}

Full genomic $R$. eutropha $\mathrm{H} 16$ oligonucleotide microarrays were used for transcription analyses (Peplinski et al. 2010). For each sample, Cy5-dUTP-labeled cDNAs were mixed with a common reference, consisting of a pool of all Cy3dUTP-labeled cDNAs which were obtained in the first biological experiment during cultivations in presence of gluconate, gluconate plus TDP, and gluconate plus DTDP, and subsequently hybridized to a microarray (Conway and Schoolnik 2003). Before hybridization, samples were denatured by incubation at $98^{\circ} \mathrm{C}$ for 5 min. Hybridization was done in Tom Freeman hybridization buffer (Fitzpatrick et al. 2005) for $15 \mathrm{~h}$ at $58^{\circ} \mathrm{C}$ with cDNA containing approximately 80 pmols of $\mathrm{Cy}-3$ and $\mathrm{Cy}-5$ in an automatic Lucidea slide processor (GE-Healthcare, Munich, Germany). Two consecutive washes each with $1 \times \mathrm{SSC}$ buffer containing $0.2 \% \mathrm{SDS}$ and then with $0.1 \times \mathrm{SSC}$ were applied to the slides. At the end, the hybridization chambers were flushed with isopropanol, and the slides were dried by evaporating the isopropanol with air. A GenePix 4000B microarray scanner (Molecular Devices, Canada) and GenePix Pro 6.0 software were used for scanning.

\section{Data normalization and filtering}

Data were normalized by multiplication of a constant factor so that the mean of the ratio of medians of all features became equal to 1 . Arrays that required a normalization factor larger than 2 were excluded from further analysis to eliminate experiments with major deviations in the applied dye incorporated in the labeled cDNA. After determining 
the fluorescence intensities of both channels, a background correction was made by subtracting the local background value from the foreground intensity. For each sample, the ratio signal intensity (Cy5)/reference (Cy3) was calculated and was taken to represent the relative RNA abundance. The extent of the gene expression levels between samples provided a measure of the overall gene expression pattern between samples. Two independent biological experiments were performed. Data were generated from the first biological experiment, resulting in averaged RNA ratios of two replicates. Only genes, which exhibited at least twofold higher signal intensities in at least the first three time points at which samples were withdrawn, were considered here. Furthermore, only those genes, whose direction of expression could be reproduced in the second biological experiment, were considered. The original raw data files have been deposited in the ArrayExpress database.

Preparation of crude extracts

Cell-free extracts were obtained by mechanical disruption. For this, $50 \mathrm{ml}$ of cell cultures were washed in $0.9 \%(w / v)$ sodium chloride, resuspended in $100 \mathrm{mM}$ Tris/ $\mathrm{HCl}(\mathrm{pH} 7.5)$ containing $10 \mu \mathrm{g}$ DNase I and passed three times through a chilled french press cell (Amicon, Silver Spring, USA) at 1,000 Mpa. Soluble protein fractions of the crude extracts were obtained in the supernatants after $1 \mathrm{~h}$ centrifugation at $100,000 \times g$ and $4^{\circ} \mathrm{C}$.

Synthesis of propionyl-CoA

Propionyl-CoA was synthesized according to Simon et al. (1983). Trilithium salt $(10 \mathrm{mg})$ of coenzyme A were dissolved in $0.5 \mathrm{M} \mathrm{K}_{2} \mathrm{CO}_{3}(\mathrm{pH} 8.0)$, and aliquots of $2 \mu \mathrm{l}$ of propionic anhydride were added while stirring on ice until no free coenzyme A was detectable with 5,5'dithiobis-(2-nitrobenzoate) (DTNB) (Ellman 1958). The $\mathrm{pH}$ of the propionyl-CoA solution was adjusted to 4.5 by addition of $1 \mathrm{~N} \mathrm{HCl}$ and was then stored at $-20^{\circ} \mathrm{C}$. The concentration of propionyl-CoA was calculated in consideration of complete substrate conversion.

\section{Enzyme assay}

Activity of 2-methylcitrate synthase was measured as previously described (Brämer and Steinbüchel 2001) by the method of Srere (1966). The cuvette $(d=1 \mathrm{~cm})$ was contained in a total volume of $1 \mathrm{ml} 2 \mathrm{mM}$ oxaloacetate, $250 \mu \mathrm{M}$ propionyl-CoA, and $2 \mathrm{mM}$ DTNB in $10 \mathrm{mM}$ Tris/ $\mathrm{HCl}(\mathrm{pH}$ 7.5). After addition of the crude extract, the increase of the absorbance at $412 \mathrm{~nm}\left(\varepsilon=13.6 \mathrm{~cm}^{2} / \mu \mathrm{mol}\right)$ was measured with a spectrophotometer (Ultrospec 2000, Amersham-Pharmacia Biotech, Freiburg, Germany).
One unit of enzyme activity was defined as the conversion of $1 \mu \mathrm{mol}$ substrate/min. The amount of soluble protein was determined by the method of Bradford (1976), using crystalline bovine serum albumin as standard.

Analysis of PHA content

Cells were harvested by centrifugation $\left(15 \mathrm{~min}, 6,000 \times \mathrm{g}, 4^{\circ} \mathrm{C}\right)$, washed in $0.9 \%(w / v)$ sodium chloride, and lyophilized. Samples were subjected to methanolysis in the presence of $85 \%(v / v)$ methanol and $15 \%(v / v)$ sulfuric acid. The resulting methyl esters of $3 \mathrm{HB}$ and 3MP were analyzed by gas chromatography (Brandl et al. 1988; Timm and Steinbüchel 1990).

\section{Results}

Polymer accumulation in R. eutropha $\mathrm{H} 16$

To analyze the accumulation of poly $(3 \mathrm{HB})$ or of the sulfurcontaining copolymer poly(3HB-co-3MP), cells of $R$. eutropha H16 were cultivated in liquid MSM containing $1 \%(w / v)$ sodium gluconate as carbon source for growth alone or in addition to either TDP or DTDP $(1 \% w / v)$ as second sulfur-containing carbon source to enable biosynthesis of poly(3HB-co-3MP). Concentration of ammonium chloride was reduced to $0.05 \%(w / v)$ to promote PHA accumulation. Samples were taken in the stationary growth phase after $24,48,72$, and $96 \mathrm{~h}$ from each culture to analyze the polymer contents and compositions (Fig. 2). In addition, samples were subjected to transcriptome analyses.

During cultivation with gluconate as sole carbon source as well as in presence of gluconate plus TDP, similar growth behavior of cells of $R$. eutropha H16 was observed. In contrast, cultivation in presence of gluconate plus DTDP resulted in a slightly diminished cell growth (Fig. 2). However, after about $34 \mathrm{~h}$ of cultivation, all cultures had reached the same density.

When cultivated with gluconate, gas chromatographic analyses revealed after $24 \mathrm{~h}$ of cultivation, a poly $(3 \mathrm{HB})$ content of about $73 \%(w / w)$ of the cell dry weight (CDW), which decreased to $68 \%$ (w/w, of CDW) after 96 h (Fig. 3). The decrease of the amount of stored poly $(3 \mathrm{HB})$ indicated degradation of small amounts of the polymer by PHB depolymerases.

When TDP or DTDP was supplemented to the medium, the copolymer poly(3HB-co-3MP) was synthesized. With TDP as second carbon source, copolymer contents of approximately $63 \%$ or $67 \%(w / w$ of CDW) were obtained after 24 and $48 \mathrm{~h}$, consisting of 3.8 and $5.3 \mathrm{~mol} \% 3 \mathrm{MP}$ $(w / w)$, respectively. Thereafter, the copolymer content of the cells decreased to $63 \%$ and $57 \%(w / w$ of CDW) after 72 
Fig. 2 Growth curves of $R$. eutropha H16 cultivated in presence of $1 \%(w / v)$ sodium gluconate (filled diamond), 1\% $(w / v)$ sodium gluconate plus $1 \%$ $(v / v)$ TDP (filled square) or DTDP (filled triangle). Samples were withdrawn after $24,48,72$, and $96 \mathrm{~h}$ of cultivation, as indicated by the arrows

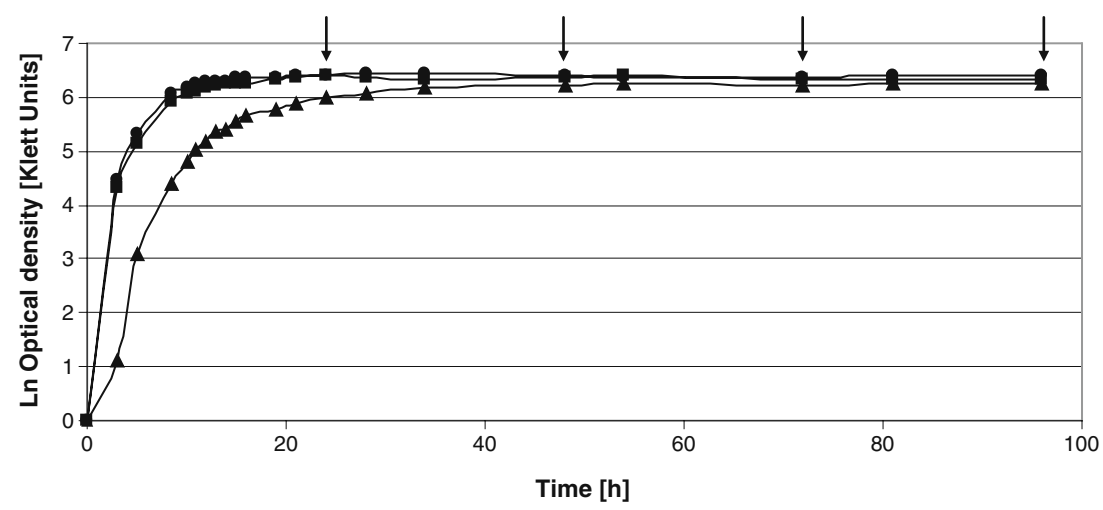

and $96 \mathrm{~h}$, respectively, whereas the molar content of $3 \mathrm{MP}$ increased at the same time to $8.1 \%$ and $10.6 \mathrm{~mol} \%(w / w)$, respectively.

Cultivation in presence of gluconate plus DTDP resulted in much lower copolymer contents, but the molar fractions of $3 \mathrm{MP}$ in the copolymers were three- to fivefold higher as compared to cells cultivated in the presence of gluconate plus TDP: after $24 \mathrm{~h}$ of cultivation, the cells had stored $22 \%$ $(w / w$ of CDW) of the copolymer with $31.7 \mathrm{~mol} \%(w / w)$ incorporated 3MP. The copolymer content increased to $35 \%$ ( $w / w$ of CDW), exhibiting $55 \mathrm{~mol} \% 3 \mathrm{MP}(w / w)$ after $72 \mathrm{~h}$ of cultivation. After $96 \mathrm{~h}$ cultivation, the copolymer content was $34 \%$ ( $w / w$ of $\mathrm{CDW}$ ), consisting of $49 \mathrm{~mol} \% 3 \mathrm{MP}$ (Fig. 3).

Studies regarding the biodegradability of PTE revealed new bacterial strains that were able to grow with poly(3HBco-3MP) as sole source for carbon and energy. Until now, intracellular degradation of this heteropolymer has not yet been investigated, but the decreasing contents of poly(3HB$c o-3 \mathrm{MP}$ ) in cells of $R$. eutropha $\mathrm{H} 16$ indicate a degradation of this copolymer.

Gene expression analyses

Genome-wide transcriptome analyses were employed to detect genes that are involved in the catabolism of TDP and DTDP. For this purpose, cells of $R$. eutropha H16 were cultivated in liquid MSM containing $0.05 \%(w / v)$ ammonium chloride to promote PHA accumulation, $1 \%(w / v)$ sodium gluconate as carbon source for growth, and either TDP or DTDP $(1 \% w / v)$ as second sulfur-containing carbon source to enable biosynthesis of poly(3HB-co-3MP). Samples were withdrawn in the stationary growth phase after $24,48,72$, and $96 \mathrm{~h}$ from each culture and were subjected to tran-
Fig. 3 Poly(3HB) and poly (3HB-co-3MP) accumulation in R. eutropha H16. Cells were cultivated in MSM under storage conditions containing (i) $1 \%$ $(w / v)$ sodium gluconate, (ii) $1 \%$ $(w / v)$ sodium gluconate plus $1 \%$ $(v / v)$ TDP, or (iii) DTDP. After $24,48,72$, and $96 \mathrm{~h}$ of cultivation, the poly $(3 \mathrm{HB})$ or poly (3HB-co-3MP) contents of the cells were analyzed by gas chromatography. Upper y-axis: Gray bars indicate the $3 \mathrm{HB}$ content (weight percent of $\mathrm{CDW}$ ) in the polymer, white bars indicate the $3 \mathrm{MP}$ content (weight percent of CDW) in the copolymer. Lower y-axis reflects the molar 3MP content of the corresponding bars above

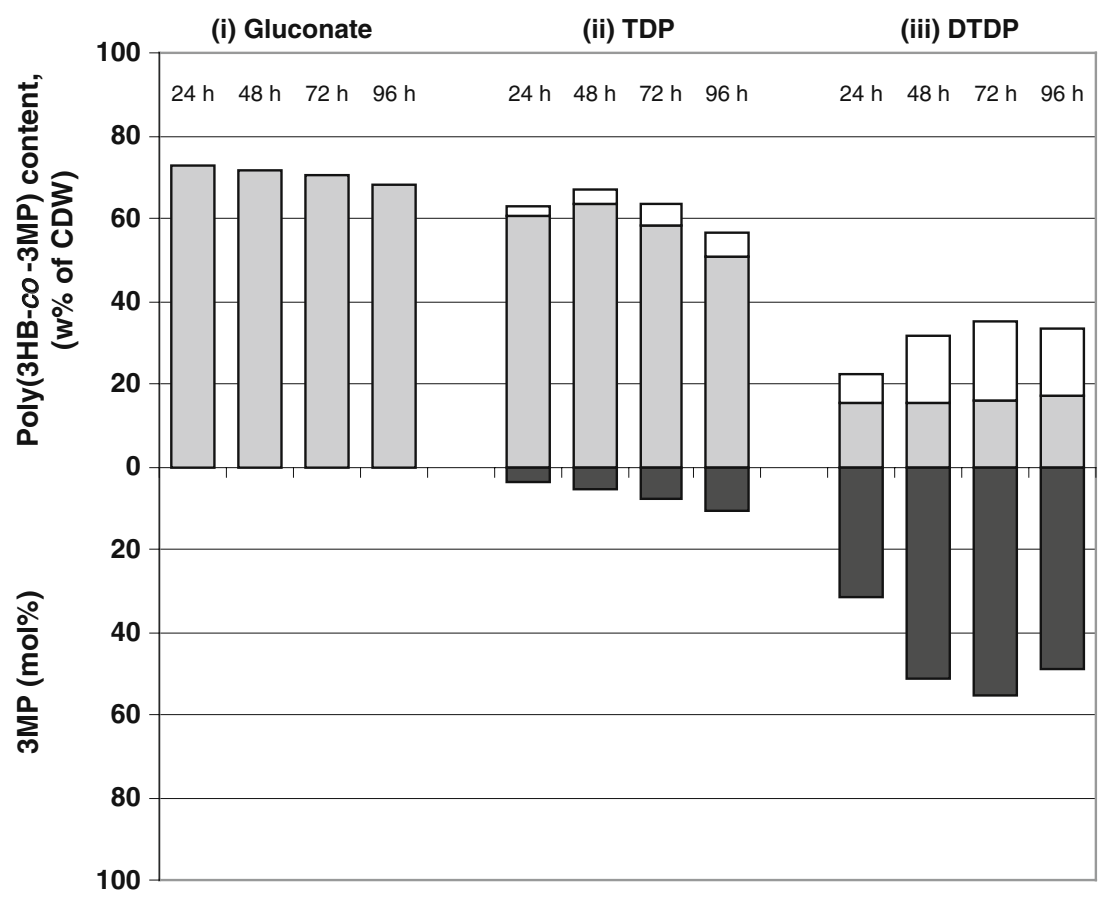


scriptome analyses. Here, the ratios of $\mathrm{Cy} 5 / \mathrm{Cy} 3$ intensities were compared to each other, to measure the overall gene expression changes between samples. Only genes, which exhibited at least twofold higher signal intensities in at least the first three time points $(24,48$, and $72 \mathrm{~h})$, were considered here, and only those genes whose direction of expression could be reproduced in the second biological experiment.

To identify genes which may be involved in the catabolism of the sulfur compounds TDP and/or DTDP, the following comparisons were carried out: cells grown on gluconate were compared to cells which were cultivated with (a) gluconate plus TDP or (b) gluconate plus DTDP. (c) In addition, differences in gene expression during growth on TDP and DTDP as second carbon source were determined, consulting the data obtained in transcriptome comparisons (a) and (b).

(a) Gluconate versus TDP

During cultivation in presence of TDP, 40 genes exhibited an at least twofold higher gene expression level in comparison to cells grown in presence of gluconate (see Online Resource 1 for details). This group includes four genes which are involved in or related to fatty acid metabolism: H16_B0782 encoding an acyltransferase exhibited increased expression level ranging from eightfold (after $24 \mathrm{~h}$ of cultivation) to 80 fold $(48 \mathrm{~h})$. Two further genes encoding acyltransferases (H16_B1292; three- to sixfold, H16_A1954; two- to fourfold) which catalyze the transfer of acyl groups to a substrate, and phaB3 encoding an acetoacetyl-CoA reductase (H16_A2171; two- to fivefold) were found to be induced during cultivation in presence of TDP (Table 1A). phaB3 represents a homolog to phaBl which is part of the phaCAB operon of $R$. eutropha H16. phaB1 is known to mediate the second step in the PHB biosynthesis, the reduction of acetoacetyl-CoA to $R$-3-hydroxybutyryl$\mathrm{CoA}$, which is then further polymerized to poly $(3 \mathrm{HB})$ by the PHB synthase PhaCl. Whereas phaCl is essential for PHB biosynthesis in R. eutropha H16, phaBl can be replaced by isoenzymes.

ORF H16_A0217 was 3- to 40-fold upregulated during cultivation in presence of TDP in comparison to gluconate. The hypothetical protein showed 54\% amino acids identical to an acyl-CoA thioesterase from Saccharomonospora viridis (YP_003134187) and comprises a HotDog domain. This domain was first observed in the structure of an E. coli thiol ester dehydratase (FabA) by Leesong et al. (1996) and is found in a diverse range of enzymes, including acylACP thioesterases, acyl-CoA thioesterases, and the 4HBT (4-hydroxybenzoate thioesterase) superfamily (Dillon and Bateman 2004).
Moreover, frnE encoding a dithiol-disulfide isomerase (H16_B2322; three- to sixfold) was detected (Table $1 \bar{A})$. FrnE is a DsbA-like protein and is presumed to be a thiol oxidoreductase. DsbA is a monomeric thiol-disulfide oxidoreductase and is known as the strongest thiol oxidant being involved in the oxidative protein-folding pathway in prokaryotes.

A strong induction at all four time points investigated was found for genes encoding an $\mathrm{ABC}$-type transporter including the permease components and the periplasmic solute-binding domain (H16_A3658-A3660; three- to ninefold).

Furthermore, two genes encoding a glutathione $S$ transferases were detected (H16_A1090, H16_B0571; three- to sixfold). The corresponding enzymes are generally known as detoxifying enzymes and are involved in the metabolism of a wide range of xenobiotic compounds. They catalyze the conjugation of these compounds with glutathione, which can then be excreted (Hayes and Pulford 1995). One further gene, encoding the peroxiredoxin bcp (H16_A0306; threefold) exhibited higher gene expression levels at all four time points. Peroxiredoxins are a ubiquitous family of thiol-specific antioxidant enzymes, sharing a redoxactive cysteine in the active site.

(b) Gluconate versus DTDP

111 genes exhibited increased expression levels during cultivation in presence of DTDP in comparison to cells cultivated in presence of gluconate (details are given in Online Resource 2). As also observed above (in (a)), genes known to be involved in fatty acid metabolism exhibited higher expression levels at all four time points. They code for an enoyl-CoA hydratase (H16_A0179, three- to fivefold), an acyldehydratase (H16_A1070, three- to fivefold) and an acetyltransferase (H16 B0782, 25- to 428-fold). Furthermore, H16_A0217 encoding the putative acylCoA thioesterase, which was already mentioned above, was also induced during cultivation in presence of DTDP (6- to 46-fold).

ahcY, encoding the $S$-adenosylhomocysteinase (H16_A0244, 6- to 13-fold) which catalyzes the reversible hydrolysis of $S$-adenosylhomocysteine to adenosine and L-homocysteine, exhibited increased expression levels. It has to be mentioned that this gene was detected in comparison (a) as well, but exhibited an at least twofold increased transcription level only in the last three time points (here, seven- to tenfold), hence, it is not listed. One further upregulated gene encodes for a rhodanese-related sulfurtransferase (H16_A0333, four- to eightfold) which is putatively catalyzing the sulfur transfer from thiosulfate to thiophilic acceptors (Ray et al. 2000). 
Table 1 Fold change of genes which were detected as upregulated during cultivation with (A) gluconate plus TDP in comparison to gluconate, (B) gluconate plus DTDP in comparison to gluconate, (C) gluconate plus TDP in comparison to gluconate plus DTDP, and (D) gluconate plus DTDP in comparison to gluconate plus TDP

\begin{tabular}{|c|c|c|c|c|c|c|}
\hline \multirow[t]{2}{*}{ ID } & \multirow{2}{*}{$\begin{array}{l}\text { Gene } \\
\text { name }\end{array}$} & \multirow[t]{2}{*}{ Annotation } & \multicolumn{4}{|c|}{ Fold change } \\
\hline & & & $24 \mathrm{~h}$ & $48 \mathrm{~h}$ & $72 \mathrm{~h}$ & $96 \mathrm{~h}$ \\
\hline
\end{tabular}

A

Genes putatively involved in the

uptake of TDP

H16_A3658

H16_A3659

H16_A3660

Genes putatively involved in the

catabolism of TDP

H16 B0782

H16_A0217

H16_A1954

H16_A2171

H16_B1292

H16_B2322

Genes putatively involved in detoxification

H16_A0306

H16_A1090

H16_B0571

B

Genes putatively involved in the uptake

of DTDP

H16_A2779

H16_A0337

Genes putatively involved in the catabolism of DTDP

H16_A0180

H16_A0181

H16_A0182

H16_A0183

H16_A0333

H16 A0161

H16_A3455

H16_B2322

H16 A0179

H16 A0217

H16_A0244

H16_A1070

H16 B0782

H16_B1784

H16_B1785

Genes putatively involved in detoxification
H16_A0705
H16_A0706
H16_A1137
H16_A3089
H16_B0451

ABC-type transporter, permease component

$\mathrm{ABC}$-type transporter, permease component

ABC-type transporter, permease component

Acetyltransferase (GNAT) family

Hypothetical membrane-associated protein

Predicted acyltransferase

phaB3 Acetoacetyl-CoA reductase

phnT Acetyltransferase (GNAT) family

frnE

Predicted dithiol-disulfide isomerase

$b c p$

Peroxiredoxin

Glutathione $S$-transferase

Glutathione $S$-transferase

Probable extracytoplasmic solute receptor

Probable extracytoplasmic solute receptor

bioA

bioF

bioD

bioB

$d s b A$

$d s b D$

frnE

Adenosylmethionine-8-amino-7-oxononanoate aminotransferase

8-amino-7-oxononanoate synthase

Dethiobiotin synthetase

Biotin synthase

Rhodanese-related sulfurtransferase

Thiol:disulfide interchange protein

Thiol:disulfide interchange protein

Predicted dithiol-disulfide isomerase

Enoyl-CoA hydratase/carnithine racemase

Hypothetical membrane-associated protein

ahcY Adenosylhomocysteinase

Acyl dehydratase

Acetyltransferase, GNAT-family

Signal transduction histidine kinase

Response regulator, OmpR-family

groES Co-chaperonin (HSP10)

groEL Chaperoning (HSP60 family)

grpE Molecular chaperone

dnaK

$\begin{array}{llll}6.28 & 3.66 & 3.64 & 3.60 \\ 6.90 & 3.34 & 6.58 & 3.44 \\ 6.90 & 4.48 & 7.86 & 9.37\end{array}$

$\begin{array}{llll}8.16 & 80.25 & 30.38 & 34.75\end{array}$

$\begin{array}{llll}3.16 & 3.11 & 40.29 & 30.94\end{array}$

$4.09 \quad 2.04 \quad 2.61 \quad \mathrm{x}$

$\begin{array}{llll}4.68 & 2.20 & 3.97 \quad \mathrm{x}\end{array}$

$\begin{array}{llll}6.36 & 2.74 & 3.46 & \mathrm{x}\end{array}$

$\begin{array}{llll}2.99 & 6.25 & 5.80 & 5.26\end{array}$

$\begin{array}{llll}3.53 & 2.99 & 3.11 & 2.70\end{array}$

$\begin{array}{llll}2.89 & 6.15 & 3.82 & 3.77\end{array}$

$\begin{array}{llll}2.78 & 5.00 & 3.56 & 2.94\end{array}$

$\begin{array}{llll}3.35 & 3.96 & 2.12 & \mathrm{x} \\ 2.62 & 3.06 & 4.44 & \mathrm{x}\end{array}$

$\begin{array}{llll}17.16 & 47.67 & 8.12 & 5.55\end{array}$

$\begin{array}{llll}5.98 & 8.22 & 2.60 & 3.57\end{array}$

$\begin{array}{lllll}5.16 & 6.49 & 4.68 & 2.15\end{array}$

$\begin{array}{llll}8.02 & 5.86 & 6.73 & 3.39\end{array}$

$\begin{array}{llll}3.59 & 6.58 & 7.55 & 7.00\end{array}$

$\begin{array}{llll}3.78 & 3.34 & 4.53 & 3.25\end{array}$

$8.19 \quad 5.70 \quad 8.79 \quad \mathrm{x}$

$\begin{array}{lllll}6.58 & 14.50 & 10.00 & 6.60\end{array}$

$\begin{array}{llll}3.25 & 4.35 & 5.07 & 2.98\end{array}$

$\begin{array}{llll}5.77 & 13.37 & 46.08 & 21.53\end{array}$

$\begin{array}{lllll}5.55 & 10.25 & 10.90 & 13.39\end{array}$

$\begin{array}{llll}4.44 & 4.70 & 2.79 & 2.59\end{array}$

$\begin{array}{llll}38.41 & 428.83 & 27.49 & 25.35\end{array}$

$\begin{array}{llll}4.17 & 8.26 & 3.62 & 2.67\end{array}$

$\begin{array}{llll}4.00 & 4.15 & 3.73 & 3.88\end{array}$

$23.51 \quad 9.41 \quad 3.03 \quad \mathrm{x}$

$\begin{array}{llll}15.68 & 2.94 & 2.49 & \mathrm{x}\end{array}$

$\begin{array}{llll}6.84 & 9.17 & 6.51 & 5.46\end{array}$

$\begin{array}{lllll}4.26 & 4.34 & 8.64 & 5.66\end{array}$

$\begin{array}{llll}4.77 & 3.68 & 2.44 & \mathrm{x}\end{array}$ 
Table 1 (continued)

\begin{tabular}{|c|c|c|c|c|c|c|}
\hline \multirow[t]{2}{*}{ ID } & \multirow{2}{*}{$\begin{array}{l}\text { Gene } \\
\text { name }\end{array}$} & \multirow[t]{2}{*}{ Annotation } & \multicolumn{4}{|c|}{ Fold change } \\
\hline & & & $24 \mathrm{~h}$ & $48 \mathrm{~h}$ & $72 \mathrm{~h}$ & $96 \mathrm{~h}$ \\
\hline H16_A1090 & & Glutathione $S$-transferase & 7.50 & 6.88 & 3.97 & 3.87 \\
\hline H16_A0306 & $b c p$ & Peroxiredoxin & 3.45 & 5.02 & 3.60 & 4.47 \\
\hline \multicolumn{7}{|l|}{$\mathrm{C}$} \\
\hline \multicolumn{7}{|c|}{$\begin{array}{l}\text { Genes putatively involved in the uptake } \\
\text { of TDP }\end{array}$} \\
\hline H16_A0357 & & $\begin{array}{l}\text { ABC-type transporter, ATPase component: } \\
\text { NitT family }\end{array}$ & 79.34 & 13.73 & 17.89 & $\mathrm{x}$ \\
\hline H16_A0358 & & $\begin{array}{l}\text { ABC-type transporter, permease component: } \\
\text { NitT family }\end{array}$ & 129.50 & 15.34 & 11.60 & $\mathrm{x}$ \\
\hline H16_A0359 & & $\begin{array}{l}\text { ABC-type transporter, periplasmic component: } \\
\text { NitT family }\end{array}$ & 107.15 & 45.76 & 6.24 & $\mathrm{x}$ \\
\hline \multicolumn{7}{|c|}{$\begin{array}{l}\text { Genes putatively involved in the catabolism } \\
\text { of TDP }\end{array}$} \\
\hline H16_B1102 & & Acetyl-CoA synthetase & 17.01 & 19.93 & 3.29 & 2.31 \\
\hline H16_A0234 & aidB & Acyl-CoA dehydrogenase, short-chain specific & 2.78 & 2.65 & 3.35 & $\mathrm{x}$ \\
\hline H16_A0280 & $s b m l$ & Methylmalonyl-Coa mutase & 9.72 & 6.11 & 4.05 & $\mathrm{x}$ \\
\hline H16_A1949 & $\operatorname{sbm} 2$ & Methylmalonyl-Coa mutase & 248.35 & 2.87 & 7.00 & $\mathrm{x}$ \\
\hline H16_A2251 & phaY1 & D-(-)-3-hydroxybutyrate oligomer hydrolase & 3.07 & 3.79 & 9.93 & $\mathrm{x}$ \\
\hline H16_B1192 & & Acyl-CoA dehydrogenase & 25.89 & 77.24 & 2.92 & $\mathrm{x}$ \\
\hline \multicolumn{7}{|l|}{$\mathrm{D}$} \\
\hline \multicolumn{7}{|c|}{$\begin{array}{l}\text { Genes putatively involved in the uptake } \\
\text { of DTDP }\end{array}$} \\
\hline H16_A2779 & & Probable extracytoplasmic solute receptor & 5.46 & 4.13 & 2.63 & $\mathrm{x}$ \\
\hline H16_A3718 & & Probable extracytoplasmic solute receptor & 5.37 & 2.01 & 2.29 & $\mathrm{x}$ \\
\hline \multicolumn{7}{|c|}{$\begin{array}{l}\text { Genes putatively involved in the catabolism } \\
\text { of DTDP }\end{array}$} \\
\hline H16_A0333 & & Rhodanese-related sulfurtransferase & 2.74 & 3.92 & 5.22 & 3.72 \\
\hline H16_A0161 & $d s b A$ & Thiol:disulfide interchange protein & 3.51 & 3.88 & 2.70 & $\mathrm{x}$ \\
\hline \multicolumn{7}{|c|}{ Genes putatively involved in detoxification } \\
\hline H16_A0705 & groES & Co-chaperonin (HSP10) & 54.77 & 8.00 & 2.85 & $\mathrm{x}$ \\
\hline H16_A0706 & groEL & Chaperonin (HSP60 family) & 21.04 & 2.99 & 2.11 & $\mathrm{x}$ \\
\hline H16_A1137 & $\operatorname{grp} E$ & Molecular chaperone & 9.46 & 9.24 & 7.60 & 2.79 \\
\hline H16_A3089 & dnaK & Molecular chaperone (HSP70) & 7.40 & 4.03 & 6.14 & 6.34 \\
\hline H16_A0183 & bioB & Biotin synthase & 7.45 & 3.32 & 4.70 & 2.59 \\
\hline
\end{tabular}

$x$ data were excluded from further analyses due to the adjusted software filter as outlined in the "Material and methods" section

$d s b A$ and $d s b D$ (H16_A0161, three- to fivefold; H16_A3455, six- to ninefold) encode for thiol-disulfide interchange proteins and are known to be involved in the oxidative protein-folding pathway in prokaryotes. DsbA is a monomeric thiol-disulfide oxidoreductase and is the strongest thiol oxidant known. The reduced and thereby active form is maintained by the membrane protein DsbD. A further gene encoding a DsbA-like protein exhibited increased expression level during cultivation on DTDP: frnE (H16_B2322, 7- to15-fold) is already mentioned above (Table 1B).

One group of genes, which were found to be upregulated during cultivation in presence of DTDP, encode for enzymes which can be classified as detoxifying or defense enzymes. First of all three genes encoding the two glutathione $S$-transferases (H16_A1090, four- to eightfold; H16_B0451, two- to fivefold) and the peroxiredoxin encoding $b c p$ (H16_A0306, three- to fivefold) exhibited increased expression levels. These enzymes were found in transcriptome comparison (a) as well. Moreover, genes encoding molecular chaperones and co-chaperones were detected (groES, H16_A0705, 3- to 24-fold; groEL, H16_A0706, two- to sixfold; dnaK, H16_A3089, fourto ninefold and grpE, H16_A1137, five- to ninefold). In general, chaperones are known as proteins that are involved in folding nascent proteins; furthermore, many chaperones protect polypeptides from denaturation and 
aggregation in the face of physical or chemical stress (Macario 1995).

The biotin operon bioFADB (H16_A0180-A0183, 2to 48-fold) was upregulated at all four time points (Table 1B). Biotin serves as a covalently bound coenzyme for several carboxylase enzymes including acetyl-CoA carboxylase, propionyl-CoA carboxylase, and pyruvate carboxylase (Hassan and Zempleni 2006). These carboxylases play an important role in fatty acid metabolism, gluconeogenesis, and other metabolic pathways.

Finally, two genes encoding probable extracytoplasmic solute receptors (H16_A2779, H16_A0337; twoto fourfold each) exhibited increased expression levels at the first three time points during cultivation in presence of DTDP. Both genes comprise a bug domain, known from representatives of Bordetella uptake genes. The genome sequence of $R$. eutropha $\mathrm{H} 16$ revealed 154 representatives of this family (Pohlmann et al. 2006; Reinecke and Steinbüchel 2009).

(c) TDP versus DTDP

The comparison of cells cultivated in presence of TDP to cells cultivated in presence of DTDP revealed 72 genes with a higher expression level in TDP cells (for more details, see Online Resource 3) and 42 genes which were upregulated in DTDP cells (Online Resource 4).

The first group included four genes involved in fatty acid metabolism: H16_A0234 (threefold), H16_B1192 (3- to 77-fold) encoding acyl-CoA dehydrogenases and the 3-hydroxybutyrate oligomer hydrolase phaY1 (H16_A2251, three- to tenfold) (Table 1C). The latter enzyme is known to be involved in the degradation of poly(3HB) in $R$. eutropha H16. Furthermore, H16_B1102 encoding an acetyl-CoA synthetase was detected (2- to 20-fold), which has an important role in glycolysis and also in the pyruvate as well as the propionate metabolism. Two further genes involved in propionate metabolism were detected, encoding a methylmalonyl-CoA mutase ( $\mathrm{sbm} 1, \mathrm{H} 16 \_\mathrm{A} 0280$, four to tenfold; sbm2, H16_A1949, 3- to 248-fold). This enzyme converts succinyl-CoA to methylmalonyl-CoA. Finally, genes for an ABC-type transporter of the NitT family (H16_A0357-A0359, 6- to 130-fold) exhibited increased expression levels at the first three time points (Table 1C).

The comparison of TDP cells to DTDP cells revealed 42 genes which were upregulated in presence ofDTDP, as mentioned above. This group comprises genes encoding the rhodanese-related sulfurtransferase (H16 A0333, three- to fivefold), the thiol-disulfide interchange protein encoded by $d s b A$ (H16 A0161, three- to fourfold), the biotin synthase BioB (H16_A0183, three-to sevenfold), and four chaperone (groES, H16_A0705, 3- to 55-fold;
groEL, H16_A0706, 2- to 21-fold; dnaK, H16_A3089, four- to sevenfold, and grpE, H16 A1137, three- to ninefold) (Table 1D). These seven genes have been detected in transcriptome comparison (b) as well and are mentioned above. Moreover, genes encoding two probable extracytoplasmic solute receptors (H16 A2779, three- to fivefold; H16_A3718, two- to fivefold) exhibited increased expression levels. The former one has already been detected in transcriptome comparison (in (b)).

\section{PrpC enzyme activity assay}

The 2-methylcitric acid cycle (MCC) mediates the conversion of propionyl-CoA to pyruvate and is the predominant pathway for the catabolism of propionic acid in bacteria and fungi (Brämer and Steinbüchel 2001; Brock et al. 2001). The key enzyme of this pathway is the methylcitrate synthase PrpC, which condensed propionyl-CoA and oxalacetate to methylcitric acid in a claisen condensation (Brock et al. 2000). The catabolism of TDP- and DTDPdegradation products via propionyl-CoA should lead to an increased activity of PrpC. Transcriptome analyses revealed no significant changes in transcription for $\operatorname{prpC}$ during cultivation in the presence of TDP or DTDP in comparison to gluconate as fold changes of approximately 1 were detected in all four time points (data not shown). Hence, a PrpC enzyme activity assay was performed. For this purpose, cells of $R$. eutropha H16 were cultivated in MSM under storage conditions with either $1 \%(w / v)$ TDP or DTDP as second, sulfur-containing carbon source to produce poly(3HB-co-3MP). After 24, 48, 72, and $96 \mathrm{~h}$ of cultivation, samples were withdrawn, and the activity of 2methylcitrate synthase was determined.

Whereas crude extracts of cells grown on gluconate revealed an average specific PrpC activity of only $0.06 \mathrm{U} /$ $\mathrm{mg}$ of protein, an approximately fourfold higher specific PrpC activity ( $0.23 \mathrm{U} / \mathrm{mg}$ of protein) was measured in the soluble fractions of cells cultivated in presence of TDP after $24 \mathrm{~h}$ of cultivation (Fig. 4). After 48 and $72 \mathrm{~h}$, the specific PrpC activity decreased but increased slightly after $96 \mathrm{~h}$ of cultivation. In contrast, crude extracts of DTDP-grown cells of $R$. eutropha $\mathrm{H} 16$ revealed a specific PrpC activity after 24 and $48 \mathrm{~h}$ of cultivation as low as gluconate-grown cells $(0.06 \mathrm{U} / \mathrm{mg}$ of protein). However, an approximately threefold higher specific PrpC activity was measured after 72 and $96 \mathrm{~h}$ of cultivation ( 0.19 and $0.15 \mathrm{U} / \mathrm{mg}$ of protein), respectively. Specific PrpC activities of cells of $R$. eutropha H16 cultivated in presence of gluconate, TDP, or DTDP are summarized in Fig. 4.

A specific PrpC activity of only $0.04 \mathrm{U} / \mathrm{mg}$ of protein in cells of $R$. eutropha H16 cultivated in the presence of 
Fig. 4 Specific enzyme activity of PrpC measured in crude extracts of $R$. eutropha H16. Cells were cultivated in MSM under storage conditions containing $(i) 1 \%(w / v)$ sodium gluconate, $(i i) 1 \%(w / v)$ sodium gluconate plus $1 \%(v / v)$ TDP, or (iii) DTDP. After 24, 48, 72, and $96 \mathrm{~h}$ of cultivation, cells were harvested, cell-free crude extracts were prepared, and the activity of 2-methylcitrate synthase was measured. Data were generated from two independent biological experiments resulting in mean values of six replicates

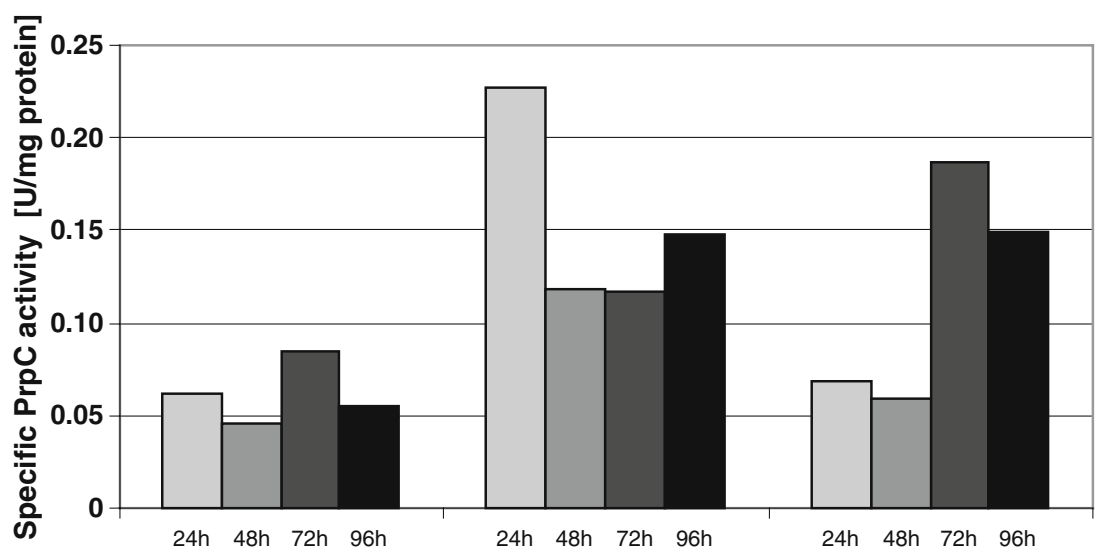

(i) Gluconate

(ii) TDP

(iii) DTDP gluconate was reported previously (Ewering et al. 2006). The low activity is most probably due to low substrate specificity of other acyl-CoA thioester-forming enzymes. Brämer and Steinbüchel (2001) revealed a specific PrpC activity of $0.354 \mathrm{U} / \mathrm{mg}$ of protein in cells of $R$. eutropha HF39, a streptomycin-resistant mutant of the wild-type H16, when cultivated in presence of propionate.

\section{Discussion}

PHB and poly(3HB-co-3MP) accumulation by $R$. eutropha H16

PTEs are only known since 2001 as sulfur-containing polymers with thioester linkages in the backbone. $R$. eutropha H16 uses 3MP, TDP, and DTDP as precursor substrates for the biosynthesis of the heteropolythioester poly(3HB-co-3MP), when a second carbon source is available for growth (Lütke-Eversloh et al. 2001b). To provide a basis to further investigate the catabolism of the above-mentioned precursor substrates and to identify genes that are putatively involved in this metabolism, genomewide transcriptome analyses were employed. For this purpose, cells of $R$. eutropha H16 were cultivated in the presence of only gluconate as carbon source for growth or in the presence of gluconate plus TDP or DTDP as precursor substrates for the incorporation of 3MP.

Diminished cell growth was obtained only during cultivation with gluconate plus DTDP (Fig. 2). As mentioned above, cleavage of DTDP into two molecules $3 \mathrm{MP}$ is proposed, whereas cleavage of TDP resulted in the release of only one molecule 3MP (Lütke-Eversloh et al. 2001a; Lütke-Eversloh and Steinbüchel 2003a). Inhibitory effects of higher concentrations of 3MP-CoA on enzymes of $\beta$-oxidation have been described previously (Sabbagh et al. 1985), possibly explaining the growth inhibition of $R$. eutropha during cultivation in presence of DTDP due to $3 \mathrm{MP}$ concentrations twice as high as in presence of TDP.

Cultivation with gluconate yielded poly $(3 \mathrm{HB})$ contents up to $73 \%(w / w)$ of $\mathrm{CDW}$ after $24 \mathrm{~h}$ of cultivation; henceforward, the polymer content decreased slowly, indicating weak poly(3HB) degradation (Fig. 3). The intracellular degradation of PHAs has been studied in detail. Different PHA depolymerases ( $p h a Z)$ and oligomer hydrolases ( $p h a Y$ ), which hydrolyze PHAs and the cleavage products, have been identified in $R$. eutropha (Jendrossek et al. 1996; Jendrossek 2002; Saegusa et al. 2001, 2002). Several studies have indicated that PHA synthesis and degradation can occur simultaneously in $R$. eutropha (Doi et al. 1990, Taidi et al. 1995), and a constitutive expression of both kinds of enzymes has been reported (Lawrence et al. 2005). In fact, synthesis and simultaneous hydrolysis of PHB make physiologically no sense as this would constitute a futile cycle, but the degradation of small amounts of PHB to maintain the basal metabolism was proposed (Peplinski et al. 2010).

Using TDP as second carbon source, a copolymer content of up to $67 \%$ was measured with up to $10.6 \mathrm{~mol} \%$ of incorporated 3MP (Fig. 3). Cultivation in the presence of DTDP resulted in lower copolymer contents of up to $35 \%$ $(w / w)$ of CDW only, but with a fivefold higher molar 3MP content of the copolymer as compared to cells cultivated in presence of TDP (Fig. 3). In this case, an increase of both the molar 3MP fraction and the copolymer content was obtained. Only after $96 \mathrm{~h}$ of cultivation, the copolymer as well as the molar 3MP content decreased. Studies regarding the extracellular biodegradability of PTE revealed new bacterial strains that were able to grow with poly(3HB-co$3 \mathrm{MP}$ ) as sole source for carbon and energy, whereas no microorganisms capable of degrading PTE homopolymers could be isolated. The studies indicated that $3 \mathrm{MP}$ containing heteropolymers are cleaved only at the oxoester bond, resulting in the release of $3 \mathrm{HB}$ moieties which are then 
utilized as carbon source. The remaining 3MP oligomers were not utilized (Elbanna et al. 2003, 2004). However, $R$. eutropha H16 is not able to grow with 3MP, TDP, or DTDP as sole source for carbon and energy, and the mobilization of stored poly(3HB-co-3MP) in this bacterium has not yet been investigated. The results of this work, however, indicate an intracellular degradation of this copolymer in $R$. eutropha H16 and confirm the assumption of Elbanna et al. (2004), that only $3 \mathrm{HB}$ units of the copolymer were mobilized, whereas 3MP oligomers are left.

\section{Uptake of TDP and DTDP}

As a prerequisite for biosynthesis of poly(3HB-co-3MP), the sulfur-containing precursors TDP and DTDP must be transported into the cells. During cultivation with TDP, two genes encoding ABC-type transport systems (H16_A36583660; H16_A0357-0359) exhibited increased transcription levels in comparison to cells cultivated in presence of gluconate or gluconate plus DTDP, respectively (Fig. 5). The latter exhibits the conserved domain cd03293 which is related to NrtD and SsuB being the ATP-binding subunits of ABC-type nitrate and sulfonate transport systems. In $E$. coli, the proteins encoded by the gene cluster $s s u E A D C B$ mediate the utilization of sulfur from aliphatic sulfonates. ssuABC constitutes an ABC-type transport system, mediating the uptake of aliphatic sulfonates, whereas $s s u D$ and $s s u E$ encode the key enzymes for the desulfonation, an $\mathrm{FMNH}_{2}$-dependent monooxygenase and an NAD(P)Hdependent FMN reductase, respectively (Eichhorn et al. 1999). Although the ABC-type transporter encoded by H16_A0357-0359 exhibited increased expression level only as compared to DTDP, transcriptome data strongly suggest that both transport systems are involved in the uptake of TDP.

During cultivation in presence of gluconate plus DTDP, three genes encoding extracytoplasmic solute receptors exhibited increased expression levels in comparison to cells cultivated in presence of gluconate or gluconate plus TDP (Fig. 5). The amino acid sequences of these genes comprise sequence similarities to representatives of the gene family of Bordetella uptake genes known as "bug receptors", which are strongly redundant in several $\beta$-Proteobacteria (Antoine et al. 2003). Some representatives of this gene family are part of operons encoding tripartite uptake transporters of the TTT family, while others are "orphan" genes (Thomas 2010). In Bordetella, Bug proteins were identified as receptor proteins for dicarboxylic compounds, and the Bug homologs BctC of Bordetella pertussis was shown to be involved in a signaling cascade as well (Antoine et al. 2005). In this context, an interesting finding was the detection of a histidine kinase (H16 B1784, threeto eightfold) and a response regulator (H16_B1785, fourfold), which exhibited increased expression levels during cultivations in the presence of gluconate plus TDP or DTDP in comparison to cells cultivated solely in presence of gluconate (Online Resource 1 and 2). These results indicate a putative signal transduction cascade with the signaling function for at least one of the cytoplasmic solute receptors and the signal transduction function for the histidine kinase and the response regulator mentioned above.

\section{Cleavage of TDP and DTDP}

As previously described, 3MP containing copolymers are synthesized in $R$. eutropha when TDP is supplemented to the media as second carbon source. Thus, an enzymatic cleavage of TDP into 3MP and 3HP by a hitherto unknown sulfide hydrolase was proposed (Lütke-Eversloh et al. 2001a). Several enzymes are described which catalyze the cleavage of structural analogs of TDP. The hydrolase $S$-adenosylhomocysteinase AhcY mediates the conversion of $S$-adenosylhomocysteine to adenosine and L-homocysteine (Palmer and Abeles 1979). In this study, ahcY was found to be upregulated during cultivation in the presence of gluconate plus DTDP but also during cultivation in the presence of gluconate plus TDP in the last three time points investigated (48, 72, and $96 \mathrm{~h}$ ). Although the enzyme was characterized as highly specific for the substrates, the upregulation of the corresponding gene is an interesting finding and requires further investigations.

Cultivation of $R$. eutropha H16 with DTDP as sulfurcontaining carbon source, resulted in the accumulation of less poly(3HB-co-3MP), while the molar 3MP fractions of the copolymers were much higher than with TDP. Very recently, data were obtained indicating the cleavage of DTDP into two molecules of 3MP by the dihydrolipoamide dehydrogenase $(p d h L)$ in $R$. eutropha (Wübbeler et al. 2010). Although the specific enzyme activity was quite low for DTDP as substrate, the reduction was unequivocally detected. These results were not supported by transcriptome data presented in this study, but further evidence for the proposal of a cleavage of the disulfide bond of DTDP into two molecules 3MP by a reductive mechanism (LütkeEversloh and Steinbüchel 2003a) was provided. The transcription analyses revealed genes coding for thioldisulfide interchange proteins (DsbA, DsbD) and a DsbA-like putative dithiol-disulfide isomerase (FrnE). DsbA and DsbD are known to be involved in correct folding of nascent proteins in the periplasm. Whereas DsbA is involved in the oxidative folding pathway, which is responsible for the formation of disulfide bonds, DsbD is involved in catalyzing intramolecular disulfide isomerization in proteins containing more than one disulfide bond. DsbA is the most oxidative oxidoreductase known, and $d s b A$ mutants of $E$. coli are hypersensitive to the 


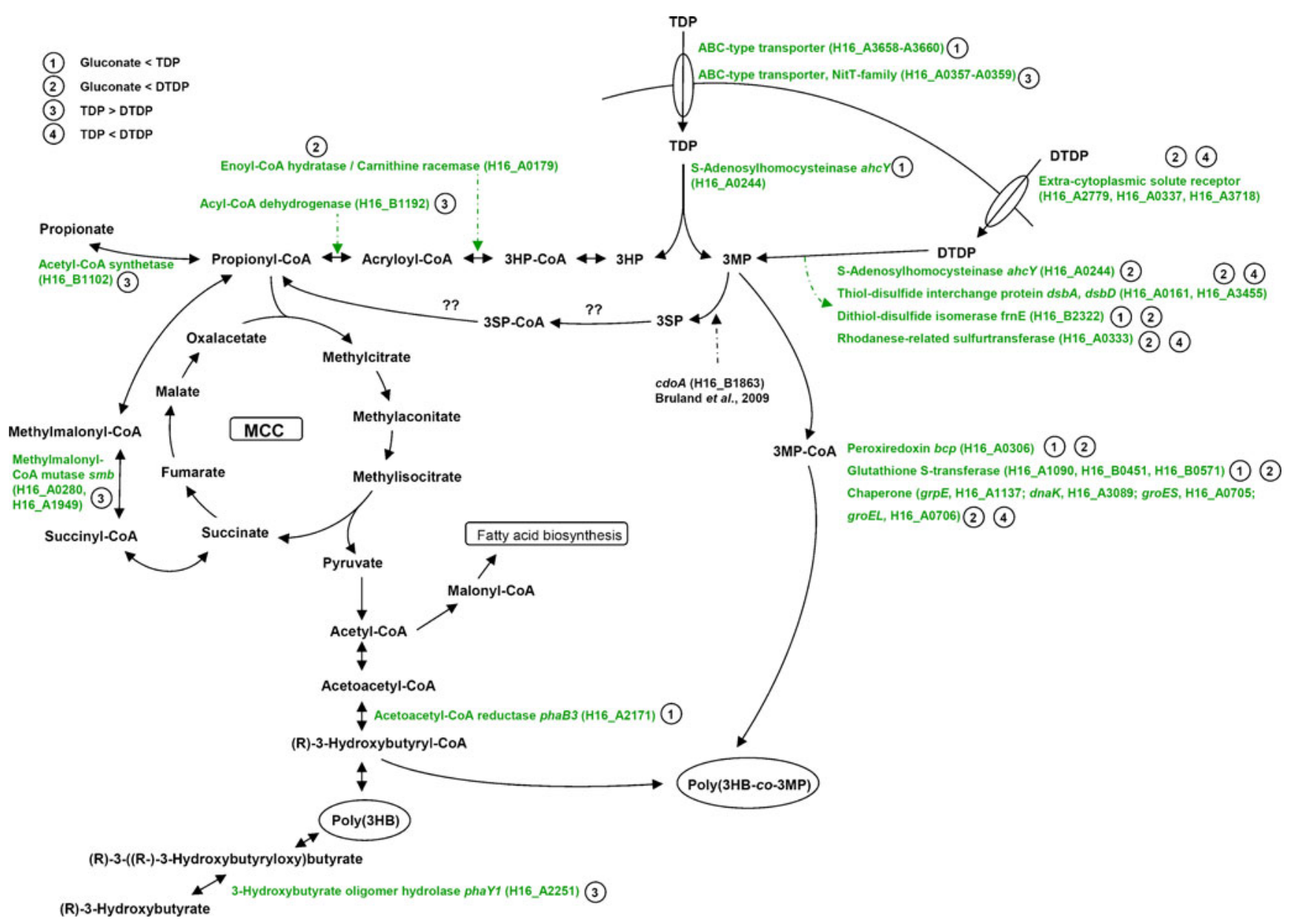

Fig. 5 Overview of the genes putatively involved in the catabolism of TDP and DTDP. The ratio Cy5 (sample)/Cy3 (common reference) was calculated and was taken to represent the relative RNA abundance. The extent of the gene expression levels between samples provided a measure of the overall gene expression pattern between samples. (1) Genes were detected as upregulated during cultivation with TDP in comparison to gluconate. (2) Genes were detected as upregulated

reductant dithiothreitol and some metal ions (Missiakas et al. 1993; Grauschopf et al. 1995; Stafford et al. 1999). Zheng et al. (1997) suggested a chaperone function of DsbA in addition to its function as an oxidoreductase. However, the data obtained by transcriptome analyses of this study clearly indicate that DsbA, DsbD, and the DsbA-like dithioldisulfide isomerase FrnE are somehow involved in the cleavage of DTDP and/or TDP. However, their direct involvement has to be further investigated.

In addition, the obtained data led to the assumption, that the rhodanese-related sulfurtransferase encoded by H16_A0333, is putatively involved in the catabolism of DTDP. This kind of enzyme catalyzes the sulfur transfer from thiosulfate to thiophilic acceptors (Ray et al. 2000), and in Pseudomonas aeruginosa, the rhodanese RhdA is involved in cyanide detoxification (Cipollone et al. 2008). during cultivation with DTDP in comparison to gluconate. (3) Genes were detected as upregulated during cultivation with TDP in comparison to DTDP. (4) Genes were detected as upregulated during cultivation with DTDP in comparison to TDP. The complete lists of all studied genes are given in the Online Resources 1-4. MCC 2methylcitric acid cycle

\section{Catabolism of TDP and DTDP}

The fate of the cleavage products $3 \mathrm{MP}$ and $3 \mathrm{HP}$ is still unknown in $R$. eutropha. During poly $(3 \mathrm{HB})$ biosynthesis in $R$. eutropha, the provided gluconate is catabolized to acetyl-CoA, which serves as a precursor substrate for synthesis of this polymer. An adequate activation of $3 \mathrm{MP}$ and $3 \mathrm{HP}$ to the corresponding $\mathrm{CoA}$ thioester, which can subsequently serve as a substrate for the PHA synthase, was proposed (Lütke-Eversloh et al. 2001a). The PHA synthase of $R$. eutropha $\mathrm{H} 16$ exhibits a very broad substrate specificity (Haywood et al. 1989) and catalyzes the biosynthesis of a wide range of different PHAs and PTEs. $3 \mathrm{HP}$ can further be catabolized to acetyl-CoA, and furthermore, it has been detected as a constituent of PHAs in R. eutropha H16 as well (Nakamura et al. 1991). 
Only very recently, new information regarding the fate of 3MP were obtained by Bruland et al. (2009). The cystein dioxygenase CdoA from $R$. eutropha $\mathrm{H} 16$ was shown to convert $3 \mathrm{MP}$ into $3 \mathrm{SP}$ in recombinant $E$. coli cells. In addition, investigations of the recently described bacteria $V$. paradoxus strain TBEA6 and A. mimigardefordensis strain $\mathrm{DPN}^{\mathrm{T}}$ led to a proposed degradation pathway from DTDP and TDP via 3MP, 3SP, and 3SP-CoA towards propionylCoA, respectively (Bruland et al. 2009; Wübbeler et al. 2008). Catabolism of propionyl-CoA via the 2-methylcitric acid cycle is very likely to occur in A. mimigardefordensis. A similar pathway in $R$. eutropha $\mathrm{H} 16$ is feasible. In addition to the incorporation into the heteropolymer, 3MP is most probably metabolized via $3 \mathrm{SP}$ and $3 \mathrm{SP}-\mathrm{CoA}$ towards propionyl-CoA, which is further catabolized via the 2-methylcitric acid cycle (Fig. 5). Enzyme activity assay of 2-methylcitrate synthase $\mathrm{PrpC}$, the key enzyme of 2methylcitric acid cycle, revealed a three- to fourfold increased specific PrpC activity in cells grown in the presence of TDP or DTDP, whereas transcriptome analyses revealed no significant upregulation of $\operatorname{prpC}$. However, an overall low specific activity for PrpC was detected, and difficulties to correlate transcriptome and proteome data has been discussed previously: differing half-life times of RNA and protein molecules and differing RNA and protein turnover can have a large impact on the obtained data (Hedge et al. 2003). As the 2-methylcitric acid cycle is the predominant pathway for the catabolism of propionic acid in bacteria and fungi, and since it occurs also in R. eutropha (Brämer and Steinbüchel 2001; Brock et al. 2001), conversion of 3MP and 3HP to propionyl-CoA is supported by this study.

Genes of fatty acid metabolism are most probably involved in the catabolism of the cleavage products $3 \mathrm{MP}$ and $3 \mathrm{HP}$ in $R$. eutropha. Transcriptome analyses revealed several genes known to be involved in fatty acid metabolism exhibiting increased expression levels during cultivation in the presence of TDP or DTDP. In particular, the acyltransferase encoded by H16_B0782 and the acyl-CoA thioesterase homolog encoded by H16_A0217 attracted attention due to the huge upregulation during both cultivation with TDP and DTDP.

\section{Stress response and detoxification}

Chemical stress occurs widely in nature. Microorganisms react, e.g., to anoxia, changes in $\mathrm{pH}$ or towards different xenobiotics by increasing the expression of stress proteins. Heat-shock proteins are a common example. Many chaperones are also stress proteins and protect polypeptides from denaturation and aggregation when facing physical or chemical stress (Macario 1995). 3MP, TDP, and DTDP exert toxic effects on cells of $R$. eutropha at concentrations higher than $0.1 \%$ or
$1.5 \%$, respectively, thereby diminishing growth (LütkeEversloh et al. 2001a). Transcriptome analyses revealed several genes coding for chaperones induced during cultivation with DTDP as compared to gluconate and TDP, respectively. Further hints for the involvement of chaperones in the degradation of DTDP were obtained. Wübbeler et al. (2008) characterized mutants of A. mimigardefordensis exhibiting insertions in genes encoding chaperones as fully or partially impaired in utilization of DTDP. In addition, chaperone activity is obviously important for degradation of dimethylsulfoniopropionate (DMSP) (Bürgmann et al. 2007). The increased expression of genes coding for glutathione $S$-transferases (GST) and peroxiredoxin is a further stress response to the cultivation with TDP and DTDP. GSTs are involved in the metabolism of a wide range of xenobiotic compounds by catalyzing the conjugation of these compounds with glutathione (Armstrong 1991). Peroxiredoxin is a representative of a ubiquitous family of thiolspecific antioxidant enzymes (Wood et al. 2003). The results of the transcriptome analyses are summarized and graphically presented in Fig. 5.

Genome-wide transcriptome analyses revealed several interesting genes with increased expression level during cultivation in presence of TDP and/or DTDP. The data strongly suggest that they are somehow involved in the catabolism of these compounds in $R$. eutropha H16. Therefore, these transcriptome analyses provided valuable hints for proteins that are required for the uptake and catabolism of these organic sulfur compounds. Extensive further investigations are now required to characterize these genes in detail and to reveal their functions in R. eutropha H16 and other bacteria. This will of course also include the generation of knockout mutants defective in the genes found in these transcriptome analyses and the characterization of the phenotypes of these mutants.

Acknowledgments The project was carried out within the framework of the Competence Network Göttingen "Genome research on bacteria" (GenoMik and Genomik Plus) financed by the German Federal Ministry of Education and Research (BMBF, FKZ-0313751) which is gratefully acknowledged. Support of this study by Jan Hendrik Wübbeler and Nadine Stöveken is gratefully acknowledged.

\section{References}

Antoine R, Jacob-Dubuisson F, Drobecq H, Willery E, Lesjean S, Locht C (2003) Overrepresentation of a gene family encoding extracytoplasmic solute receptors in Bordetella. J Bacteriol 185:1470-1474

Antoine R, Huvent I, Chemlal K, Deray I, Raze D, Locht C, JacobDubuisson F (2005) The periplasmic binding protein of a tripartite tricarboxylate transporter is involved in signal transduction. J Mol Biol 351:799-809

Armstrong RN (1991) Glutathione $S$-transferases: reaction mechanism, structure and function. Chem Res Toxicol 4:131-140 
Bradford MM (1976) A rapid and sensitive method for the quantitation of microgram quantities of protein utilizing the principle of protein-dye binding. Anal Biochem 72:248-254

Brämer CO, Steinbüchel A (2001) The methylcitric acid pathway in Ralstonia eutropha: new genes identified involved in propionate metabolism. Microbiology 147:2203-2214

Brandl H, Gross RA, Lenz RW, Fuller RC (1988) Pseudomonas oleovorans as a source of poly( $\beta$-hydroxyalkanoates) for potential applications as biodegradable polyesters. Appl Environ Microbiol 54:1977-1982

Brock M, Fischer R, Linder D, Buckel W (2000) Methylcitrate synthase from Aspergillus nidulans: implications for propionate as an antifungal agent. Mol Microbiol 35:961-973

Brock M, Darley D, Textor S, Buckel W (2001) 2-Methylisocitrate lyase from the bacterium Escherichia coli and the filamentous fungus Aspergillus nidulans: characterization and comparison of both enzymes. Eur J Biochem 268:3577-3586

Bruland N, Wübbeler JH, Steinbüchel A (2009) 3-Mercaptopropionate dioxygenase, a cysteine dioxygenase homologue, catalyzes the initial step of 3-mercaptopropionate catabolism in the 3, 3'thiodipropionic acid degrading bacterium Variovorax paradoxus. J Biol Chem 284:660-672

Bürgmann H, Howard EC, Ye W, Sun F, Sun S, Napierala S, Moran MA (2007) Transcriptional response of Silicibacter pomeroyi DSS-3 to dimethylsulfoniopropionate (DMSP). Environ Microbiol 9:2742-2755

Cipollone R, Ascenzi P, Tomao P, Imperi F, Visca P (2008) Enzyme detoxification of cyanide: clues from Pseudomonas aeruginosa rhodanese. J Mol Microbiol Biotechnol 15:199-211

Conway T, Schoolnik GK (2003) Microarray expression profiling: capturing a genome-wide portrait of the transcriptome. Mol Microbiol 47:879-889

Dillon SC, Bateman A (2004) The HotDog fold: wrapping up a superfamily of thioesterases and dehydratases. BMC Bioinform 5:109

Doi Y, Segawa A, Kawaguchi Y, Kunioka M (1990) Cyclic nature of poly(3-hydroxyalkanoate) metabolism in Alcaligenes eutrophus. FEMS Microbiol Lett 55:165-169

Eichhorn E, van der Ploeg JR, Leisinger T (1999) Characterization of a two-component alkanesulfonate monooxygenase from Escherichia coli. J Biol Chem 274:26639-26646

Elbanna K, Lütke-Eversloh T, Van Trappen S, Mergaert J, Swings J, Steinbüchel A (2003) Schlegelella thermodepolymerans gen. nov., sp. nov., a novel thermophilic bacterium that degrades poly(3-hydroxybutyrate-co-3-mercaptopropionate). Int J Syst Evol Microbiol 53:1165-1168

Elbanna K, Lütke-Eversloh T, Jendrossek D, Luftmann H, Steinbüchel A (2004) Studies on the biodegradability of polythioester copolymers and homopolymers by polyhydroxyalkanoate (PHA)-degrading bacteria and PHA depolymerases. Arch Microbiol 182:212-225

Ellman GL (1958) A colorimetric method for determining low concentrations of mercaptans. Arch Biochem Biophys 74:443450

Ewering C, Heuser F, Benölken JK, Brämer CO, Steinbüchel A (2006) Metabolic engineering of strains of Ralstonia eutropha and Pseudomonas putida for biotechnological production of 2methylcitric acid. Metab Eng 8:587-602

Fitzpatrick JM, Johnston DA, Williams GW, Williams DJ, Freeman TC, Dunnea DW, Hoffmann KF (2005) An oligonucleotide microarray for transcriptome analysis of Schistosoma mansoni and its application/use to investigate gender-associated gene expression. Mol Biochem Parasitol 141:1-13

Grauschopf U, Winther JR, Korber P, Zander T, Dallinger P, Bardwell JCA (1995) Why is DsbA such an oxidizing disulfide catalyst? Cell 83:947-955
Hassan YI, Zempleni J (2006) Epigenetic regulation of chromatin structure and gene function by biotin. J Nutr 136:1763-1765

Hayes JD, Pulford DJ (1995) The glutathione $S$-transferase supergene family: regulation of GST and the contribution of the isoenzymes to cancer chemoprotection and drug resistance. Crit Rev Biochem Mol Biol 30:445-600

Haywood G, Anderson A, Dawes E (1989) The importance of PHBsynthase substrate-specificity in polyhydroxyalkanoate synthesis by Alcaligenes eutrophus. FEMS Microbiol Lett 57:1-6

Hedge PS, White IR, Debouck C (2003) Interplay of trancriptomics and proteomics. Curr Opin Biotechnol 14:647-651

Jendrossek D (2002) Extracellular polyhydroxyalkanoate depolymerases: the key enzymes of PHA degradation. In: Doi Y, Steinbüchel A (eds) Biopolymers, volume $3 \mathrm{~b}$ : polyesters IIproperties and chemical synthesis. Wiley-VCH, Weinheim, pp 41-84

Jendrossek D, Handrick R (2002) Microbial degradation of polyhydroxyalkanoates. Annu Rev Microbiol 56:403-432

Jendrossek D, Schirmer A, Schlegel HG (1996) Biodegradation of polyhydroxyalkanoic acids. Appl Microbiol Biotechnol 46:451463

Kawada J, Lütke-Eversloh T, Steinbüchel A, Marchessault RH (2003) Physical properties of microbial polythioesters: characterization of poly(3-mercaptoalkanoates) synthesized by engineered Escherichia coli. Biomacromolecules 4:1698-1702

Kim DY, Lütke-Eversloh T, Elbanna K, Thakor N, Steinbüchel A (2005) Poly(3-mercaptopropionate): a nonbiodegradable biopolymer? Biomacromolecules 6:897-901

Lawrence AG, Schoenheit J, He A, Tian J, Liu P, Stubbe J, Sinskey AJ (2005) Transcriptional analysis of Ralstonia eutropha genes related to poly- $(R)$-3-hydroxybutyrate homeostasis during batch fermentation. Appl Microbiol Biotechnol 68:663-672

Leesong M, Henderson BS, Gillig JR, Schwab JM, Smith JL (1996) Structure of a dehydratase-isomerase from the bacterial pathway for biosynthesis of unsaturated fatty acids: two catalytic activities in one active site. Structure 4:253-264

Lemoigne M (1926) Produits de deshydration et de polymerization de lácide $\beta$-oxybutyrique. Bull Soc Chim Biol 8:770-782

Lindenkamp N, Peplinski K, Volodina E, Ehrenreich A, Steinbüchel A (2010) Multiple $\beta$-ketothiolase deletion mutants of Ralstonia eutropha: impact on the composition of 3-mercaptopropionic acod-containing copolymer. Appl Environ Microbiol. doi:10.1128/ AEM.01058-10

Lütke-Eversloh T, Steinbüchel A (2003a) Novel precursor substrates for polythioesters (PTE) and limits of PTE biosynthesis in Ralstonia eutropha. FEMS Microbiol Lett 221:191-196

Lütke-Eversloh T, Steinbüchel A (2003b) Polythioesters. In: Matsumura S, Steinbüchel A (eds) Biopolymers, vol. 9. Wiley-VCH, Weinheim, pp 63-80

Lütke-Eversloh T, Steinbüchel A (2004) Microbial polythioester. Macromol Biosci 4:165-174

Lütke-Eversloh T, Bergander K, Luftmann H, Steinbüchel A (2001a) Identification of a new class of biopolymer: bacterial synthesis of a sulfur-containing polymer with thioester linkages. Microbiology 147:11-19

Lütke-Eversloh T, Bergander K, Luftmann H, Steinbüchel A (2001b) Biosynthesis of poly(3-hydroxybutyrate-co-3-mercaptobutyrate) as a sulfur analogue to poly(3-hydroxybutyrate) (PHB). Biomacromolecules 2:1061-1065

Lütke-Eversloh T, Kawada J, Marchessault RH, Steinbüchel A (2002) Characterization of biological polythioesters: physical properties of novel copolymers synthesized by Ralstonia eutropha. Biomacromolecules 3:159-166

Macario AJL (1995) Heat-shock proteins and molecular chaperones: implications for pathogenesis, diagnostics, and therapeutics. Int $\mathrm{J}$ Clin Lab Res 25:59-70 
Missiakas D, Georgopoulos C, Raina S (1993) Identification and characterization of the Escherichia coli gene $d s b B$, whose product is involved in the formation of disulfide bonds in vivo. Proc Natl Acad Sci USA 90:7084-7088

Nakamura S, Kunioka M, Doi Y (1991) Biosynthesis and characterization of bacterial poly(3-hydroxybutyrate-co-3-hydroxypropionate). Macromol Rep A28:15-24

Palmer JL, Abeles RH (1979) The mechanism of action of $S$ adenosylhomocysteinase. J Biol Chem 254:1217-1226

Peplinski K, Ehrenreich A, Döring C, Bömeke M, Reinecke F, Hutmacher C, Steinbüchel A (2010) Genome-wide transcriptome analyses of the 'Knallgas' bacterium Ralstonia eutropha H16 with regard to polyhydroxyalkanoate metabolism. Microbiology (SGM) 156:2136-2152

Pohlmann A, Fricke WF, Reinecke F, Kusian B, Liesegang H, Cramm R, Eitinger T, Ewering C, Pötter M, Schwartz E, Strittmatter A, Voß I, Gottschalk G, Steinbüchel A, Friedrich B, Bowien B (2006) Genome sequence of the bioplastic-producing "Knallgas" bacterium Ralstonia eutropha H16. Nat Biotechnol 24:12571262

Pötter M, Steinbüchel A (2005) Poly(3-hydroxybutyrate) granuleassociated proteins: impacts on poly(3-hydroxybutyrate) synthesis and degradation. Biomacromolecules 6:552-560

Ray WK, Zeng G, Potters MB, Mansuri AM, Larson TJ (2000) Characterization of a 12-kilodalton rhodanese encoded by $g l p E$ of Escherichia coli and its interaction with thioredoxin. J Bacteriol 182:2277-2284

Rehm BHA (2003) Polyester synthase: natural catalysts for plastics. Biochem J 376:15-33

Reinecke F, Steinbüchel A (2009) Ralstonia eutropha strain H16 as model organism for PHA metabolism and for biotechnological production of technically interesting biopolymers. J Mol Microbiol Biotechnol 16:91-108

Sabbagh E, Cuebas D, Schulz H (1985) 3-Mercaptopropionic acid, a potent inhibitor of fatty acid oxidation in rat heart mitochondria. J Biol Chem 260:7337-7342

Saegusa H, Shiraki M, Kanai C, Saito T (2001) Cloning of an intracellular poly [D(-)-3-hydroxybutyrate] depolymerase gene from Ralstonia eutropha $\mathrm{H} 16$ and characterization of the gene product. J Bacteriol 183:94-100

Saegusa H, Shiraki M, Saito T (2002) Cloning of an intracellular D(-)3-hydroxybutyrate oligomer hydrolase gene from Ralstonia eutropha $\mathrm{H} 16$ and identification of the active site serine residue by site-directed mutagenesis. J Biosci Bioeng 94:106-112

Schlegel HG, Gottschalk G, von Bartha R (1961) Formation and utilization of poly- $\beta$-hydroxybutyric acid by Knallgas bacteria (Hydrogenomonas). Nature 191:463-465
Simon R, Priefer U, Pühler A (1983) A broad host range mobilization system for in vivo genetic engineering: transposon mutagenesis in Gram negative bacteria. Bio/Technology 1:784-791

Slater T, Houmiel KL, Tran M, Mitsky TA, Taylor NB, Padgette SR, Gruys K (1998) Multiple $\beta$-ketothiolases mediate poly $(\beta$ hydroxyalkanoate) copolymer synthesis in Ralstonia eutropha. J Bacteriol 180:1979-1987

Srere PA (1966) Citrate-condensing enzyme-oxaloacetate binary complex. J Biol Chem 241:2157-2165

Stafford SJ, Humphreys DP, Lund PA (1999) Mutations in $d s b A$ and $d s b B$, but not in $d s b C$, lead to an enhanced sensitivity of Escherichia coli to $\mathrm{Hg}^{2+}$ and $\mathrm{Cd}^{2+}$. FEMS Microbiol Lett 174:179-184

Steinbüchel A (2005) Non-biodegradable biopolymers from renewable resources: perspectives and impacts. Curr Opin Biotechnol 16:607-613

Steinbüchel A, Valentin HF (1995) Diversity of bacterial polyhydroxyalkanoic acids. FEMS Microbiol Lett 128:219-228

Taidi B, Mansfield D, Anderson AJ (1995) Turnover of poly(3hydroxybutyrate) (PHB) and its influence on the molecular mass of the polymer accumulated by Alcaligenes eutrophus during batch culture. FEMS Microbiol Lett 129:201-206

Thomas GH (2010) Homes for the orphans: utilization of multiple substrate-binding proteins by ABC transporter. Mol Microbiol 75:6-9

Timm A, Steinbüchel A (1990) Formation of polyesters consisting of medium-chain-length 3-hydroxyalkanoic acids from gluconate by Pseudomonas aeruginosa and other fluorescent pseudomonads. Appl Environ Microbiol 56:3360-3367

Wood ZA, Schröder E, Harris JR, Poole LB (2003) Structure, mechanism and regulation of peroxiredoxins. Trends Biochem Sci 28:32-40

Wübbeler JH, Lütke-Eversloh T, Van Trappen S, Vandamme P, Steinbüchel A (2006) Tetrathiobacter mimigardefordensis sp. nov., isolated from compost, a betaproteobacterium capable of utilizing the organic disulfide 3, 3'-dithiodipropionic acid. Int J Syst Evol Microbiol 56:1305-1310

Wübbeler JH, Bruland N, Kretschmer K, Steinbüchel A (2008) A novel pathway for the catabolism of the organic sulfur compound 3, 3'-dithiodipropionic acid via 3-mercaptopropionic acid and 3sulfinopropionic acid to propionyl-CoA by the aerobic bacterium Tetrathiobacter mimigardefordensis strain DPN7. Appl Environ Microbiol 74:4028-4035

Wübbeler JH, Raberg M, Brandt U, Steinbüchel A (2010) Dihydrolipoamide dehydrogenases of Advenella mimigardefordensis and Ralstonia eutropha catalyze cleavage of 3,3'-dithiodipropionic acid into 3-mercaptopropionic acid. Appl Environ Microbiol. doi:10.1128/AEM.01706-10

Zheng WD, Quan H, Song JL, Wang CC (1997) Does DsbA have chaperone-like activity? Arch Biochem Biophys 337:326-331 